\title{
Understanding poverty persistence in Spain
}

\author{
Sara Ayllón
}

Received: 29 December 2010 / Accepted: 6 July 2012 / Published online: 7 August 2012

(C) The Author(s) 2012. This article is published with open access at SpringerLink.com

\begin{abstract}
The aim of this paper is to study the mechanisms behind poverty persistence in Spain. We examine the importance of past poverty experiences for explaining current poverty as opposed to observed and unobserved individual heterogeneity. Our results are based on the model proposed by Cappellari and Jenkins (J Appl Econometr 19:593-610, 2004a) that estimates poverty transitions while simultaneously controlling for attrition and initial conditions. We find that about $50 \%$ of aggregate state dependence is genuine: poverty in a given year increases in itself the chances of experiencing poverty again in the future. The remainder is explained, among other characteristics, by living with a head of household who has no educational qualifications, being an immigrant or cohabiting with teenagers. Our findings call for a comprehensive and coordinated strategy against poverty that should focus equally on income-support policies and on enhancing those characteristics that best protect against economic hardship. From a methodological point of view, we learn that unobservables affecting initial conditions and sample retention are exogenous to those related to poverty transience. However, results prove to be sensitive to the choice of poverty line.
\end{abstract}

Keywords Poverty persistence $\cdot$ State dependence $\cdot$ Attrition $\cdot$ Initial conditions

\section{JEL Classification $\quad \mathrm{I} 32 \cdot \mathrm{D} 31 \cdot \mathrm{C} 33$}

\section{Introduction}

For several reasons, it is crucial to take a longitudinal perspective in the analysis of poverty in any given context. First, the study of the dynamic aspects of poverty leads to

\footnotetext{
S. Ayllón $(\bowtie)$

Department of Economics and EQUALITAS, Universitat de Girona,

C/Universitat de Girona 10, 17071 Girona, Spain

e-mail: sara.ayllon@udg.edu
} 
a better understanding of the nature of poverty and the type of individuals that suffer it. A more precise description of poverty is enhanced by learning from the determinants of poverty entries and exits. Second, dynamic analyses distinguish between chronic and transient poverty. In this regard, it is commonly agreed that experiencing poverty for a long period of time is worse than being temporarily below the poverty line. Third, poverty dynamics enable the study not only of the symptoms but also the processes that lead to economic deprivation (Jenkins 2011). And, fourth, results on poverty dynamics are informative for policy design. If poverty is transitory, emphasis should be given to short-term income-support policies that help to cope with temporary earnings shocks. However, if poverty is suffered chronically, poor individuals could be better helped by policies that enhance those characteristics that protect them from adversity-for example, employability through education or training.

This paper studies poverty dynamics in Spain by focusing on transitions into poverty and, especially, persistence. ${ }^{1}$ Compared to other European countries, poverty in Spain is characterised by high levels of incidence and major recurrence (OECD 2008; Cantó et al. 2012). This means that the poverty line is crossed more often than in countries with similar poverty rates. At the same time, a sizeable percentage of the population is persistently below the poverty line. Recent estimates by Jenkins and Van Kerm (2011) find that $11.0 \%$ of Spaniards are at-risk-of persistent poverty (at least 3 years out of a 4-year window) — only below Estonia, Portugal, Latvia, Ireland and Italy out of 21 European countries analysed. In this paper, we are concerned with the mechanisms behind poverty chronicity. On the one hand, persistent poverty could be due to genuine state dependence: experiencing poverty in a given period increases in itself the chances of suffering poverty again in the future. On the other hand, certain observed and unobserved characteristics that persist over time could make someone more likely to be successively poor. Learning to distinguish between the two also has important policy implications. If poverty persistence is mostly due to past poverty experiences, policy design should focus on income transfers. Helping individuals to move above the poverty line will break the poverty spiral in the future. However, if poverty persistence is explained by heterogeneity, policies should centre on enhancing the individual and household characteristics that prevent poverty. Therefore, the main contribution of our paper is to examine the importance of the two sources of poverty persistence by measuring, for the first time, the degree of poverty genuine state dependence in Spain and derive policy recommendations.

With this objective in mind, we apply to Spanish data a model proposed in the literature by Cappellari and Jenkins (2004a) that estimates poverty entries and persistence and deals with the initial conditions problem and the possibility of non-random attrition of the sample. It is important to account for initial conditions because the initially poor may be a non-random sample of the population and ignoring this may bias our poverty inflow and outflow estimates. Furthermore, estimates of poverty dynamics should control for the fact that transitions are only observed for those individuals in the survey at $t-1$ and at $t$ and again these may be a selected group of the original sample. We assess the endogeneity of both processes to poverty transitions by freely estimating the correlations between unobservables affecting each outcome. As far as

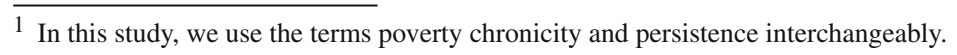


we know, a similar application to the Spanish case does not exist in the literature and we will therefore be able to assess whether the determinants of poverty dynamics are robust to the methodology used.

Our main findings show that about $50 \%$ of the probability of being poor in a given period is due to past poverty experiences in Spain: there is a sizeable scarring effect by which poor individuals enter a vicious circle from which it is difficult to escape. The remaining state dependence is positively associated with a head of household having low educational qualifications, being of immigrant origin and teenagers being in the household, and is negatively associated with the number of workers or cohabiting with young people. This means that anti-poverty policies in Spain should equally focus on income-support policies-breaking the poverty spiral-and on social policies that enhance protective factors-education, training, housing, etc.

From a methodological point of view, we show that unobserved heterogeneity affecting poverty status in the base year and/or sample retention are exogenous to unobservables related with poverty transitions when using the standard poverty line. These results support previous estimates for poverty in Spain based on the European Community Household Panel that did not account for possibly correlated unobservables between transience, attrition and initial conditions. However, when the poverty line is set at 40 or $50 \%$ of the median of equivalent household income we find that individuals that are more likely to be initially poor are less likely to remain poor compared to the non-poor-an example of Galtonian regression towards the mean. Similarly, retained individuals are less likely to remain poor or fall into poverty. Failure to account for both endogeneities would underestimate our poverty persistence and entry estimates when poverty is more extremely defined.

The paper is structured as follows. Section 2, after this introduction, briefly revises the existing literature on poverty dynamics devoted to the Spanish case. Section 3 presents the data and some methodological choices, while Sect. 4 shows poverty transitions on a descriptive level. Section 5 explains the model by Cappellari and Jenkins (2004a) used in this work and Sect. 6 discusses the empirical results. Section 7 concludes.

\section{Review}

Part of the literature on poverty transience in the Spanish case focuses on the description of trends. Cantó et al. (2003) using the Encuesta Contínua de Presupuestos Familiares (ECPF) for the 1985-1995 period find that the decline in poverty of the late 1980s may be associated with high exit rates rather than a major improvement in the situation of those at risk of falling into it. However, the increase in poverty risk experienced by Spaniards in the early 1990s was due both to the increase in poverty entries and, especially, to the reduction in poverty exits. Bárcena et al. (2006) update these results by running a similar descriptive analysis for the 1993-2000 period with data from the ECHP. ${ }^{2}$

\footnotetext{
2 The first estimates of poverty entries and exits in Spain using data from the ECHP are given in García Mainar and Toharia (1998).
} 
As for the characterization of poverty dynamics, Cantó (2003) assesses the importance of demographic and socio-economic characteristics for the probability of poverty exit. She finds that less than $10 \%$ of the transitions out of poverty are linked to demographic events while the remainder are related to changes in the labour market or the receipt of social assistance benefits.

In relation to methodological questions, Cantó et al. (2006) show that the choice of quarterly or annual income has important consequences for poverty estimates. The exit rate is fairly similar for both income definitions but the entry rate is higher for quarterly income. Furthermore, they show that only half of those classified as leavers by one income definition are equally classified by the other, and the misclassification is even stronger when considering poverty entries.

Moreover, Cantó et al. (2012) study the profiles of poor individuals according to the length of their poverty experiences. They distinguish between the chronic and transitory poor and among the latter, those that are recurrent (more than one spell in poverty) or not. They argue that Spain has relatively low levels of chronicity but a high percentage of recurrent poor-especially among households with a head below 65 years of age, with low educational qualifications, and that is self-employed or cohabits with young children. However, note that they also find that $15.5 \%$ of Spaniards lived below the poverty line at least 4 out of 7 years during the same period than the one analysed in this paper - the highest percentage of all the countries they study except for Portugal.

Researchers have also studied duration dependence in the poverty status. Cantó (2002) assesses the importance of time in poverty on the measurement of entries and exits. She proposes a discrete time duration-dependent $n$-order Markov process with heterogeneity jointly estimating exits and (re)entries. Results show that one third of households that escape poverty soon return to it while if they manage to be out of poverty for 1 year, the chances of falling back into it strongly decrease. Similarly, Bárcena et al. (2004) argue for the need to consider not only poverty status at $t$ conditional on poverty status at $t-1$, but also the time spent in the same poverty status as $t-1$. The probability of poverty transition prove to be smaller when accounting for time inertia. More recently, Arranz and Cantó (2011) proposed a multi-state multiple transition discrete hazard regression model that controls not only for observed and unobserved heterogeneity but also for the length of the current poverty spell, the time between spells, the occurrence of multiple spells and the accumulation of poverty spells. They find evidence of negative duration dependence-longer poverty spells reduce the probability of exit and increase the rixk of (re)entry. Among other results, second and third poverty spells are found to be shorter than the first, and non-poverty spells are of longer duration than poverty spells.

Amuedo-Dorantes and Serrano-Padial (2010), on the other hand, are concerned with feedback effects and examine the poverty implications for past and current temporary employment in Spain. They find that having a temporary contract not only increases the probability of current poverty but also of future poverty via an indirect effect that increases the chances of having a type of contract in the future with a higher poverty risk (while no direct effect of a past temporary contract on poverty is found).

However, in most studies referred to Spain, initial conditions are not explicitly modelled together with poverty transitions with the exception of Gradín and Cantó (2011). In this case, the authors study the difference in the probability of being poor 
depending on the presence of children in the household by means of a Heckman model and a random effects dynamic probit that allows the authors to control for unobserved heterogeneity and initial conditions. However, the paper does not offer a measure of genuine state dependence or an explicit control for attrition. Moreover, in Arranz and Cantó (2011), initial conditions are taken into account by merely adding three variables to their estimation related to the health of the members of the household, the presence of working-age females and the head's unemployment spells in the last 5 years. We believe the methodology used in this paper offers a more precise control.

As for attrition, Cantó et al. (2003) and Cantó (2003) do take into account potential non-randomness of sample reduction through the construction of their own sample weights (also see, for a similar strategy, Ayala et al. 2006). The inconvenience of this strategy is that the control is over observed heterogeneity only. Finally, Cantó et al. (2007) estimate poverty exits using a Heckman selection model that controls for retention. With data from the ECPF for the 1985-1995 period, they find that retention and poverty exit equations are independent in most of their model specifications. Nevertheless, we are still left with the question as to whether there is a correlation between unobservables affecting attrition that also influence poverty transience for the later period between 1994 and 2000.

Finally, and regarding the application of the same econometric strategy, apart from the original article by Cappellari and Jenkins (2004a) that studies the British case, Buddelmeyer and Verick (2008) have also used it for Australia, Fusco and Islam (2011) for Luxembourg and Faye et al. (2011) in the case of Nairobi's slums. Their results are commented throughout the paper. Variations in the model for the analysis of poverty can be found in Van Kerm (2004) for the case of Belgium and in Nilsson (2012) for a study of poverty state dependence among twins in Sweden.

\section{Data and definitions}

\subsection{Data}

The data set used in the analysis is the Spanish component of the European Community Household Panel (ECHP) which is a harmonised cross-national longitudinal survey collected across all members of the (former) European Union-15. The panel runs from 1994 to 2001. Data is based on a standardised questionnaire that collects information related to income, education, employment, household structure, housing, health, social relations and individual satisfaction. The target population consists of all private households throughout the national territory in every country and hence, indigenous households are left out of the analysis.

\subsection{Unit of analysis and sample size}

Although the household is the unit of measurement for income, we examine poverty dynamics at the individual level. As argued in OECD (2001), this methodological choice offers the advantage of giving greater weight to larger families and makes it possible to track the poverty status of individuals when family structure changes 
Table 1 Number of sample observations

\begin{tabular}{lcc}
\hline Wave & Individuals & Total observations \\
\hline $1(1994)$ & 9.443 & 9.433 \\
$2(1995)$ & 8.914 & 18.347 \\
$3(1996)$ & 8.243 & 26.590 \\
$4(1997)$ & 7.691 & 34.281 \\
$5(1998)$ & 7.319 & 41.600 \\
$6(1999)$ & 6.926 & 48.526 \\
$7(2000)$ & 6.791 & 55.317 \\
Total & 55.317 & \\
\hline
\end{tabular}

Individuals between 25 and 64 years old (included)

Source: Own construction using the ECHP, 1994-2001. Note that the last poverty transitions take place between 1999 and 2000 and therefore the total number of transitions observed is 48.526 when allowing transitions to missing

(e.g. divorce, marriage, leaving parental home, etc.). Furthermore, and following previous literature, we restrict our analysis to the population between 25 and 64 years old. As indicated by Arranz and Cantó (2007), it is among the Spanish working-age population that transitory or short-term poverty mainly takes place-and this is explicitly what we model in this study. See also, OECD (2001) for similar evidence. Moreover, we exclude individuals aged 65 or over in order to avoid the impact of retirement decisions on poverty dynamics.

Table 1 shows the number of sample observations used for the empirical analysis. Note that apart from the age of the individuals, no other restrictions are imposed on our working sample. ${ }^{3}$ We allow individuals into the panel even if we know their poverty status for one single year and they transit to missing in the following one. Thus, our panel is unbalanced and maximizes the use of the information available in the survey. We consider this feature of our analysis to be a major advantage because it does not incur possible sample selection problems and neither raises questions about representativeness.

\subsection{Poverty}

A person is considered poor if the equivalent income of the household where she/he lives is below the poverty line defined as $60 \%$ of the median of that distribution. The threshold is relative to time so there is a poverty line for each of the years analysed. We use the modified OECD equivalent scale as the scaling factor that takes into account the economies of scale within the household by giving a weight of 1 to the first adult, 0.5 to the remaining adult members of the household and 0.3 to children under 14

\footnotetext{
3 For instance, Arranz and Cantó (2007) need to limit their analysis to individuals present in the survey in 1994. Bárcena et al. (2006) restrict their analysis to adults participating during the eight waves of the panel which considerably cuts their working sample. Cantó et al. (2003) with data from the ECPF limit the sample to those individuals answering at least five quarterly questionnaires. It is sometimes argued that results from bigger samples referred to shorter windows may be more representative and reliable than from smaller samples for longer windows (see Jenkins 2011).
} 
years of age. ${ }^{4}$ Moreover, we assume that all incomes are pooled together and shared equally among household members.

\subsection{Income in the ECHP}

The income distribution used in our analysis is net annual household income which adds the income from all possible sources for all household members. As in other surveys, annual income variables are collected retrospectively in the ECHP. For instance, in wave 1, run in 1994, annual income variables refer to incomes obtained by household members in 1993. Neglecting this time lag between the period to which household income refers (year $t-1$ ) and the period to which household composition and other variables of interest relate (year $t$ ) would introduce some bias. Therefore, net household income in year $t-1$ is finally constructed as the sum of net personal income reported at $t$ of the individuals that were present in the household at $t-1$ (see Debels and Vandecasteele 2005; Arranz and Cantó 2007). ${ }^{5}$ This approach makes it possible to build household equivalent income at each year with the household composition (and equivalence scale) referring to the same year.

Note, however, that the choice of this income distribution implies, on the one hand, that only seven waves of the panel can be used in our analysis, and, on the other, that a certain number of missing values arise when one of the members of the household does not report his/her income at $t$, either because of attrition or because this person refuses to collaborate with this part of the questionnaire. Table 9 of the Appendix can be used to check how differences in the population headcount ratio are very small either using or not the income distribution with or without time lag in relation to the equivalence scale. Table 10, on the other hand, shows how the use of the corrected household income definition increases the number of transitions to missing by about $2.9 \%$. Nonetheless, we use an estimation technique that explicitly accounts for sample attrition (see below).

\section{Poverty dynamics in Spain: a description}

The aim of this section is to briefly describe poverty transitions in Spain during the analysed period for the proposed sample. Table 2 shows the poverty status of Spanish individuals aged 25-64 at time $t$ conditional on their status at $t-1$. The first panel shows the results when missing income information is not taken into account and the second displays them when we do.

First of all, it is worth noting the important difference in the probability of being poor at time $t$ depending on the poverty status at $t-1$. The chances of an individual being poor at $t$ were $58.41 \%$ if s/he was already poor at $t-1$ but only $8.17 \%$ if

\footnotetext{
4 These methodological options follow the recommendations of the European Commission for the analysis of poverty and social exclusion in the European Union (Laeken indicators).

5 Debels and Vandecasteele (2008) propose a more accurate measure that accounts for changes in household composition within waves.
} 
Table 2 Poverty status at $t$ conditional of poverty status at $t-1$ in Spain without and with income missing data, 1994-2000

Source: Own construction using the ECHP, 1994-2001.

Individuals aged 25-64.

$N=41.457$ observations when not taking into account the missing information and $N=48.526$ observations when allowing transitions to missing

\begin{tabular}{llll}
\hline Year & \multicolumn{3}{l}{$t$} \\
\cline { 2 - 4 } & Not poor & Poor & Missing \\
\hline$t-1$ & & & \\
Not poor & 91.83 & 8.17 & - \\
Poor & 41.59 & 58.41 & - \\
Total & 83.26 & 16.74 & - \\
$t-1$ & & & \\
Not poor & 78.52 & 6.98 & 14.49 \\
Poor & 35.68 & 50.11 & 14.22 \\
Total & 71.23 & 14.32 & 14.45 \\
\hline
\end{tabular}

not. ${ }^{6}$ One of the objectives of this study is to address the possibility of an endogenous selection mechanism occurring by which individuals observed poor at $t$ perhaps are over (or under) represented at $t-1$.

Secondly, it is interesting to observe the pattern of transitions to missing. Results show that $14.49 \%$ of individuals that are not poor at $t-1$ are no longer observed at $t$. Among those observed as poor, the percentage is 14.22. At first sight, it seems that sample retention is exogenous to poverty status at $t-1$. In the following section, however, we explicitly address the question of potential non-random selection of the sample. ${ }^{7}$

Table 3 sheds additional light on the different transition probabilities year by year. As can be observed, entry rates fluctuate between 6.17 and $8.18 \%$ while exit rates do so between 31.09 and $41.15 \%$. However, as similarly pointed out by Arranz and Cantó (2007), there is no clear trend of poverty outflows and inflows throughout the period and it is difficult to distinguish, on a descriptive level, a different sample retention process for those who are poor and not poor at $t-1 .^{8}$

Finally, Table 4 presents household income level as a percentage of the median of those individuals entering or escaping poverty, which enables assessment of the income level that is the starting point for a transition. As shown, the chances of falling into poverty are highest for those with incomes between 60 and $70 \%$ of the median while they are much smaller as income increases. Interestingly though, such a clear pattern does not emerge in the case of poverty exits: the opportunities for escaping poverty are greater for those individuals with an income below $20 \%$ of the median than for those between 20 and $40 \% .{ }^{9}$ We give another explanation for this finding below.

\footnotetext{
6 These results are fairly similar to those obtained by Bárcena et al. (2006) with the same dataset as they estimate an entry rate of $8.07 \%$ and an exit rate of $39.80 \%$. Note, however, that they base their estimates on a balanced panel for individuals that are in the panel for eight consecutive waves and are aged 16 or above. 7 In OECD (2001) it is argued that "Attrition bias may be particularly acute for the ECHP since attrition rates are quite high for some of the participating countries (...) and the poverty population appears to drop out of the sample at a disproportionate rate in most of these countries" (OECD 2001, p. 43). However, from this descriptive analysis we do not find such a clear pattern in the Spanish case.

8 Arranz and Cantó (2007) with data from the ECHP also argue that "[...], the probability of attrition does not appear to be determined by the individual poverty situation" (Arranz and Cantó 2007, p. 13).

9 Bárcena et al. (2006) in their descriptive analysis find an even greater similarity between the exit rate for Spanish households with income below $10 \%$ of the median and those between 50 and $60 \%$ of the same.
} 
Table 3 Poverty status at $t$ conditional of poverty status at $t-1$ in Spain with income missing data year by year, 1994-2000

Source: Own construction using the ECHP, 1994-2001.

Individuals aged 25-64. $N=48.526$ observations

\begin{tabular}{|c|c|c|c|c|}
\hline Year & & Not poor & Poor & Missing \\
\hline \multirow{3}{*}{1994} & 1995 & & & \\
\hline & Not poor & 79.43 & 7.41 & 13.17 \\
\hline & Poor & 41.15 & 43.88 & 14.97 \\
\hline \multirow{3}{*}{1995} & 1996 & & & \\
\hline & Not poor & 75.95 & 8.18 & 15.87 \\
\hline & Poor & 31.09 & 54.10 & 14.81 \\
\hline \multirow{3}{*}{1996} & 1997 & & & \\
\hline & Not poor & 79.34 & 6.17 & 14.50 \\
\hline & Poor & 34.52 & 50.00 & 15.48 \\
\hline \multirow{3}{*}{1997} & 1998 & & & \\
\hline & Not poor & 78.76 & 6.69 & 14.55 \\
\hline & Poor & 36.36 & 50.64 & 13.01 \\
\hline \multirow{3}{*}{1998} & 1999 & & & \\
\hline & Not poor & 76.99 & 6.54 & 16.47 \\
\hline & Poor & 35.37 & 47.74 & 16.89 \\
\hline \multirow{3}{*}{1999} & 2000 & & & \\
\hline & Not poor & 81.00 & 6.62 & 12.38 \\
\hline & Poor & 34.83 & 56.25 & 8.91 \\
\hline
\end{tabular}

Table 4 Income level as percentage of the median of individuals entering and exiting poverty

\begin{tabular}{|c|c|c|c|c|}
\hline \multirow[t]{2}{*}{ Household income as $\%$ of the median } & \multicolumn{2}{|l|}{ Entry into poverty } & \multicolumn{2}{|l|}{ Exit from poverty } \\
\hline & $\%$ of individuals & Entry rate & $\%$ of individuals & Exit rate \\
\hline$[\succ 0, \leq 10]$ & & & 5.22 & 38.88 \\
\hline$[\succ 10, \leq 20]$ & & & 5.29 & 36.33 \\
\hline$[\succ 20, \leq 30]$ & & & 8.30 & 31.31 \\
\hline$[\succ 30, \leq 40]$ & & & 14.23 & 35.52 \\
\hline$[\succ 40, \leq 50]$ & & & 25.93 & 42.24 \\
\hline$[\succ 50, \leq 60]$ & & & 41.04 & 48.54 \\
\hline$[\succ 60, \leq 70]$ & 32.98 & 33.53 & & \\
\hline$[\succ 70, \leq 80]$ & 20.82 & 18.78 & & \\
\hline$[\succ 80, \leq 90]$ & 13.80 & 13.36 & & \\
\hline$[\succ 90, \leq 100]$ & 9.26 & 8.71 & & \\
\hline \multirow[t]{2}{*}[\geq100]{} & 23.13 & 2.87 & & \\
\hline & 100.00 & 8.17 & 100.00 & 41.59 \\
\hline
\end{tabular}

Source: Own construction using the ECHP, 1994-2001. Individuals aged 25-64

Footnote 9 continued

The authors argue that temporary income variations, transitory absence of income and measurement error may explain why exits do not seem to depend on the poverty gap. Cantó et al. (2003), however, explain that the origin may be in demographic and labour market transitions. 


\section{The model}

In this work we study poverty transitions by following the proposed model by Cappellari and Jenkins (2004a) which allows the estimation of state dependence and the characterization of poverty persistence and poverty entries while at the same time accounts for attrition and initial conditions. ${ }^{10}$ The model belongs to the Markovian transition models approach. ${ }^{11}$

We build on a system of simultaneous equations that includes a first-order poverty transitions equation for all the pooled annual transitions, the poverty status at $t-1$ (in order to account for the initial conditions problem) and an equation for sample retention (to consider potential non-random attrition) plus the correlations between the three equations that are allowed to be freely estimated. ${ }^{12}$ We refer the interested reader to the original article for a full econometric illustration of the model.

Let's first define the poverty transitions equation. We assume that in period $t$ individuals can be characterized by a latent poverty propensity $p_{i t}^{*}$ that takes the form:

$$
\begin{aligned}
& p_{i t}^{*}=\left[\left(P_{i t-1}\right) \alpha_{1}^{\prime}+\left(1-P_{i t-1}\right) \alpha_{2}^{\prime}\right] z_{i t-1}+\omega_{i t} \\
& P_{i t}=I\left(p_{i t}^{*} \succ 0\right)
\end{aligned}
$$

where $i=1,2, \ldots, N$ refers to individuals, $\alpha_{1}^{\prime}$ and $\alpha_{2}^{\prime}$ are column vectors of parameters, $z_{i t-1}$ is the vector of explanatory variables and $\omega_{i t}$ the error term. Note that this specification implies that two sets of coefficients are estimated: if $P_{i t-1}=1, \quad \alpha_{1}^{\prime} z_{i t-1}$ is relevant and refers to poverty persistence characteristics; instead if $P_{i t-1}=0, \alpha_{2}^{\prime} z_{i t-1}$ is estimated and accounts for poverty entry characteristics. Also the vector of explanatory variables always refers to $t-1$ in order to reduce endogeneity/simultaneity problems with poverty transitions (see Jenkins 2000; Cantó 2003). ${ }^{13}$ Furthermore, $\omega_{i t}$ can be written as $\omega_{i t}=\zeta_{i}+\tau_{i t}$ where the first term is the individual specific effect that stands for all unobserved determinants of conditional poverty that are time-invariant for a given individual (e.g. ability, motivation, etc.). ${ }^{14}$ The second term is the usual white noise error. Both parts of the error term are

\footnotetext{
10 See Cappellari and Jenkins (2002) for a less technical version of the paper.

11 Other types of models have become popular in the analysis of poverty transience in the last decades even when most of them developed first in a different context: covariance structure models (Lillard and Willis 1978; Duncan and Rodgers 1991; Biewen 2005), hazard regression models (Stevens 1999; Devicienti 2001; Fourage and Layte 2003), random effects panel models (Arulampalam et al. 2000; Biewen 2009; Poggi 2007) and dynamic microsimulation models (Burgess and Propper 1998; Aassve et al. 2006), to name some of the most influential. See Jenkins (2000) for a review of the different strategies used to model poverty transitions.

12 Note that the inclusion of a retention equation allows us the use of an unbalanced panel and therefore to draw on all the information available in the panel.

13 We do not include as explanatory variables events taking place between $t-1$ and $t$ in order to avoid contemporaneously correlated regressors.

14 We suppose that the unobserved heterogeneity of conditional poverty is common in the case of poverty entry and poverty persistence. Van Kerm (2004), on the contrary, builds on a system of equations where the poverty entry rate is estimated separately from the persistence and the individual-specific effects are different in each case. Conceptually we find it easier to think of a shared individual unobserved heterogeneity for exits and (re)entries given it is a time-invariant concept.
} 
supposed to be normally distributed. $I\left(p_{i t}^{*} \succ 0\right)$ is a binary indicator function equal to one if the latent conditional poverty propensity is positive and equal to zero otherwise.

Our second equation accounts for (possibly) non-random attrition of the sample. ${ }^{15}$ Thus, we are considering the possibility that retention is not exogenous to unobserved characteristics. The equation models the probability to observe the poverty status of an individual both at $t-1$ and at $t$ and it can be defined as follows,

$$
\begin{aligned}
r_{i t}^{*} & =\varphi^{\prime} w_{i t-1}+\mu_{i t} \\
R_{i t} & =I\left(r_{i t}^{*} \succ 0\right)
\end{aligned}
$$

where $r_{i t}^{*}$ is the latent probability of consecutive participation (retention) with known poverty status, $w_{i t-1}$ is the vector of explanatory variables, $\varphi$ is the vector of parameters and $\mu_{i t}$ is the error term. Again, $\mu_{i t}$ can be written as $\mu_{i t}=\psi_{i}+\lambda_{i t}$, being the first term, the individual-specific effect and the second, the white noise error. Both parts of the error term are assumed to follow a normal distribution. $I\left(r_{i t}^{*} \succ 0\right)$ is a binary indicator function.

A third equation allows to account for the initial conditions problem which arises because the start of the observation window may not be the same than the start of the poverty experience. It is worth noting that, in this work, initial conditions refer to the base year poverty status of each poverty transition and not to the first period observed as in Wooldridge's tradition (see Wooldridge 2005; Devicienti 2001). The equation enables to account for unobserved characteristics possibly endogenous to poverty status at base year. Thus, we assume that in period $t-1$, individuals can be characterized by a latent poverty propensity which is defined as,

$$
\begin{aligned}
& p_{i t-1}^{*}=\beta^{\prime} x_{i t-1}+u_{i t-1} \\
& P_{i t-1}=I\left(p_{i t-1}^{*} \succ 0\right)
\end{aligned}
$$

where $x_{i t-1}$ is the vector of explanatory variables that both describe the individual and his/her household, $\beta$ the vector of parameters and $u_{i t-1}$ the error term. Further, $u_{i t-1}$ can be written as $u_{i t-1}=\eta_{i}+\delta_{i t-1}$, where the first term is the individual-specific effect and the second term is the white noise error. Both $\eta_{i}$ and $\delta_{i t-1}$ are assumed to be normally distributed. And, $I\left(p_{i t-1}^{*} \succ 0\right)$ is a binary indicator function equal to one if the latent base year poverty propensity is positive and equal to zero otherwise.

Moreover, the model allows the three random effects to be freely correlated. If it turns that they are, both selection processes are endogenous to poverty transitions and the estimation of a univariate probit would lead to inconsistent estimators of the parameters of interest (see Cappellari and Jenkins 2006). If all the correlations are zero, we could actually estimate the equations separately. Thus, given the mentioned assumptions, we define,

15 Cappellari and Jenkins (2004b) discriminate between attrition due to drop-out of the sample and economic item non-response when modelling low pay transitions among British men aged 18-64 showing a negligible impact on the estimates. 


$$
\begin{aligned}
& \rho_{1}=\operatorname{cov}\left(\psi_{i}, \eta_{i}\right)=\operatorname{corr}\left(\mu_{i t}, u_{i t-1}\right) \\
& \rho_{2}=\operatorname{cov}\left(\zeta_{i}, \psi_{i}\right)=\operatorname{corr}\left(\omega_{i t}, \mu_{i t}\right) \\
& \rho_{3}=\operatorname{cov}\left(\zeta_{i}, \eta_{i}\right)=\operatorname{corr}\left(\omega_{i t}, u_{i t-1}\right)
\end{aligned}
$$

where $\rho_{1}$ summarises the association between the unobservable individual-specific factors related to the consecutive participation of a certain individual in the sample and those determining the base year poverty status. If $\rho_{1}$ is positive (negative) it means that the individuals that are more likely to be consecutively participating in the sample and their household informs of their income are also more (less) likely to be initially poor. Similarly, $\rho_{2}$ summarises the association between unobservable individual specific factors determining the poverty transitions and those related with retention of a given individual. If $\rho_{2}$ is positive (negative) it means that those individuals more likely to be consecutively poor-or fall into poverty - are also more (less) likely to be income retained in the sample. Finally, $\rho_{3}$ summarises the association between unobservable factors determining poverty transitions and those determining base year poverty status. If $\rho_{3}$ is positive (negative) those individuals more likely to be transiting into poverty are also more (less) likely to be observed initially poor. Note that the interpretation of these correlations refers only to unobserved heterogeneity factors and not to observed characteristics we control for in the model.

Once the model is estimated, we can derive the transition probabilities. The persistence probability is given by,

$$
\begin{array}{r}
s_{i t}\left(z_{i t-1}, x_{i t-1}\right) \equiv \operatorname{Pr}\left(P_{i t}=1 \mid P_{i t-1}=1\right) \\
=\frac{\Phi_{2}\left(\alpha_{1}^{\prime} z_{i t-1}, \beta^{\prime} x_{i t-1}, \rho_{3}\right)}{\Phi\left(\beta^{\prime} x_{i t-1}\right)}
\end{array}
$$

And, the entry probability by,

$$
\begin{aligned}
e_{i t}\left(z_{i t-1}, x_{i t-1}\right) & \equiv \operatorname{Pr}\left(P_{i t}=1 \mid P_{i t-1}=0\right) \\
& =\frac{\Phi_{2}\left(\alpha_{1}^{\prime} z_{i t-1},-\beta^{\prime} x_{i t-1},-\rho_{3}\right)}{\Phi\left(-\beta^{\prime} x_{i t-1}\right)}
\end{aligned}
$$

where $\Phi(\cdot)$ and $\Phi_{2}(\cdot)$ are the cumulative density functions of the univariate and bivariate standard normal distributions, respectively. Note that this estimation technique allows to predict what would have been the conditional poverty probability of individuals that actually attrit.

The model is estimated by Maximum Simulated Likelihood (MSL) using a Geweke-Hajivassiliou-Keane (GHK) simulator. ${ }^{16}$ Differently from the original article, we have used Halton draws instead of pseudo-random ones. ${ }^{17}$ Antithetics is also

\footnotetext{
16 The model has been estimated using the ml commands available in Stata ${ }^{\circledR}$ and following the instructions in Cappellari and Jenkins (2003). Cappellari and Jenkins (2006) The maximization technique used is the modified Newton-Raphson algorithm, default in Stata®. See also Gould and Sribney (1999) for more information on $\mathrm{ml}$ use.

17 In simulation, draws from a density are used to calculate the average of a statistic over that density. As proven by Train (2003), MSL is consistent, asymptotically normal, efficient and asymptotically equivalent
} 
applied. ${ }^{18}$ As argued by Cappellari and Jenkins (2006), Halton draws are more effective than pseudo-random ones because they provide the same accuracy with a smaller number of draws which saves computational time. ${ }^{19}$ We do take into account for intra-household correlation in poverty status by using robust standard estimates and by clustering with the household identification number of the first year they participate in the survey.

As indicated by Wooldridge (2002), in order to identify the model we need to use exclusion restrictions. In the case of retention, we require a variable that explains why an individual is more or less likely to attrit but that, at the same time, has no influence on the probability of persistence or entry into poverty. In our case, we have used a dummy variable that identifies original sample members - as suggested by Cappellari and Jenkins (2004a) — together with a set of dummies describing the mode of interviewing. It has been shown that individuals that participate in the first wave of survey panels are more likely to continue participating. It is also reasonable to believe that those individuals answering a self-administered questionnaire, a telephone or a proxy interview as opposed to a face-to-face personal interview might be less interested in the survey project or have less time for it and therefore may be less likely to be retained in the future (see, Nicoletti and Peracchi 2005, and references therein). Coefficients in Table 6 show this is actually the case.

The instruments for the initial conditions are more difficult to find, especially because the ECHP does not collect family background information (as used in Cappellari and Jenkins 2004a or Fusco and Islam 2011). Neither it is an easy exercise in conceptual terms: there is a need to find a variable that influences the chances of being poor at a given point in time but that does not affect the probability of poverty status changing. Our final estimation includes a dummy in the initial conditions equation that identifies whether the head of household suffers or not from a chronic disease.

\section{Footnote 7 continued}

to Maximum Likelihood (ML) as long as the number of draws used in the simulation $(R)$ rises faster than the square root of the sample size $(\sqrt{N})$. In other words, the bias between MSL and ML diminishes as more draws are used in the simulation. See also Chapter 5 in Greene (2000). Furthermore, we make use of the programme mdraws made available by Cappellari and Jenkins (2006) for Stata ${ }^{\circledR}$ users to generate the draws. The primes used for the creation of the draws are 2, 3 and 5 and we present results for 100 draws-though similar results were obtained when we used 50, 75 and 125 draws. Haan and Uhlendorff (2006) argue that the number of draws should not be an integer multiple of any of the primes used, however we run the model with a prime number of draws and obtained almost identical results. Moreover, and as explained in Train (2003), given that the simulated log-likelihood function is a sum over observations of the log of simulated probabilities, if the draws are taken in such a way that negative correlation over observations is created, then the variance of the sum is lower. And this is precisely what Halton sequences do: they induce a negative correlation over observations. Halton draws are created to fill the unit interval evenly with elements placed equidistantly apart. Each cycle covers the areas not covered by previous cycles. Because Halton sequences in our study are created over 3 dimensions, we use the option burn to eliminate the initial part of the sequences as it is customary (see Train 2003, p. 230).

18 Antithetic draws are obtained by creating various types of mirror images of every draw (see Train 2003, p. 219). That way, the 100 Halton draws created per each of the 3 dimensions are finally 200 per equation. Train (2003) argues that the antithetics substantially improve the estimation of probit models.

19 Cappellari and Jenkins (2006) show that calculations based on 1,000 pseudo-random draws get very close to those derived using directly the bivariate normal probability distribution function as opposed to 50 pseudo-random draws. However, they also show that 100 Halton draws get even closer. 
This variable serves as a proxy for background information related to health as we assume that individuals only state that they have a chronic disease if it is a condition that they have had for a long period of time, probably prior to the start of the survey. ${ }^{20}$ The validity of the instrument is confirmed in the following section.

There are several advantages to the methodology adopted in our study. First, and as noted in Biewen (2009), it circumvents the strict exogeneity assumption by which there must not be any feedback from poverty in a given period to future values of the explanatory variables. In the model just presented, by definition, changes in employment status or family structure are not allowed to affect poverty until the following period. Second, the model adapts well to different panel data structures given that it only requires pooled transitions from the same individual. ${ }^{21}$ Third, the methodology enables the estimation of state dependence through the different explanatory variables and not only as one estimated parameter of the lagged dependent variable (which is interpreted as genuine state dependence) as in the random-effects probit models proposed by Wooldridge (2005) or Stewart (2007). Fourth, we can obtain comparable estimates for poverty entry and persistence. Fifth, attrition is explicitly modelled and not only allowed to depend on the initial conditions as in Wooldridge's tradition. And, finally, Cappellari and Jenkins's model does not encounter problems with left-censoring so individuals that are always poor or never poor are included in the estimates.

On the contrary, we are aware that the most important drawback of the model may be the impossibility of controlling for duration dependence in poverty status. The dynamics that the model can estimate are always between $t-1$ and $t$, which is therefore not as sophisticated as in hazard regression or variance component models. Moreover, as Jenkins (2011) explains: "Markovian models assume that the accumulated impact of a person's history of poverty (and non-poverty) is expressed entirely by last year's poverty status" (Jenkins 2011, p. 332). As already mentioned, Arranz and Cantó (2011), to cite the most recent study of the Spanish case, have shown the importance of duration in poverty dynamics analyses (see also Devicienti and Gualtieri 2007). However, Devicienti (2001) also finds that controlling for unobserved characteristics reduces the importance of duration dependence. The model we apply in this study does not substitute the key findings obtained from duration dependence models. Rather, we believe it can complement some of their results. Moreover, Cappellari and Jenkins's model requires valid instruments that may be difficult to find in different contexts and/or data sets. Lastly, it is computationally more demanding than the estimation of a random-effect probit model. ${ }^{22}$

\footnotetext{
20 Heckman (1981) suggested that initial conditions for labour market outcomes could be instrumented with information prior to labour market entry. In our case, however, such a time line cannot be considered because one can enter poverty at any moment in life.

21 Note that this is going to be particularly important for future research with the EU-SILC (Community Statistics on Income and Living Conditions) because most countries follow an integrated design by which households participate in the panel at the most for four consecutive waves and each year $25 \%$ of the sample is substituted with new respondents. Moreover, initial conditions are going to be different for each rotational group.

22 For example, a random-effect probit model can easily be estimated using the command xtprobit in Stataß.
} 


\section{Empirical results}

We present the empirical findings by focusing first on the model specification results in order to assess how well the model fits the data. ${ }^{23}$ Second, we introduce the findings relative to state dependence, to move on to a discussion of the model coefficients and marginal effects. Finally, some robustness checks are commented.

\subsection{Model specification}

Table 5 first presents the probability predictions of the model computed as shown in Eqs. (10) and (11). Poverty persistence is 0.611 which compares closely to the (unweighted) raw probability of 0.596 (or 0.605 if we compare to those retained). ${ }^{24}$ Similarly, the predicted proportion of individuals that enter poverty status at $t$ (given that they were not poor at $t-1$ ) is 0.089 , which is close to the 0.081 from the raw data. As for the probability of exit, a predicted 0.388 compares to 0.404 . And finally, for the proportion of individuals being retained, the value of the predicted probability and the raw value are both 0.855 . The same occurs for the proportion of initially poor $(0.171)$.

Second, we test for possible ignorability of initial conditions and attrition. Table 5 also presents the results relative to the correlations when the poverty threshold is set at $60 \%$ of the median of the household equivalent income distribution. As shown, none of the estimated correlations is significantly different from zero. Thus, unobserved heterogeneity affecting retention is not related to that which affects initial poverty status or poverty transience which implies that the retention and the initial conditions equations could actually have been estimated separately from that of transience. ${ }^{25,26}$ The exogeneity tests of the two selection processes considered could not be rejected by the Wald tests conducted. These results necessarily support previous poverty dynamics estimates for the Spanish case derived from the ECHP that did not consider unobserved heterogeneity related to attrition and initial conditions when using the standard poverty line. On the other hand, it strengthens the use of simpler computational strategies such as that proposed by Wooldridge (2005) for the estimation of genuine state dependence.

As commented, in order to identify the model, it is crucial to find valid instruments. Wald tests indicate that the fact that the head of household suffers from a chronic disease could be excluded from the transitions equation, and the same occurs for the original sample member dummy and the type of questionnaire answered. On the contrary, both sets of instruments increase the precision of the initial conditions and retention equations, respectively.

\footnotetext{
${ }^{23}$ Model assumptions such as, for instance, normality of random effects, presented in the previous section are presumed from this point onwards.

${ }^{24}$ Note that the comparison is always with an unweighted probability as we do not have weights for those individuals that attrit. Thus, the unweighted probabilities differ slightly from those presented in Table 2.

25 Differences in the predicted probabilities of persistence and entry among all individuals and the retained sample are negligible which confirms the ignorability of retention.

26 Buddelmeyer and Verick (2008) did not find significant correlations in the Australian case either, but argue that joint estimation improves efficiency.
} 
Table 5 Predicted probabilities, estimates of model correlations, exogeneity of initial conditions and sample retention tests, validity of instruments, state dependence estimates and poverty duration predictions ( $p$-values in brackets)

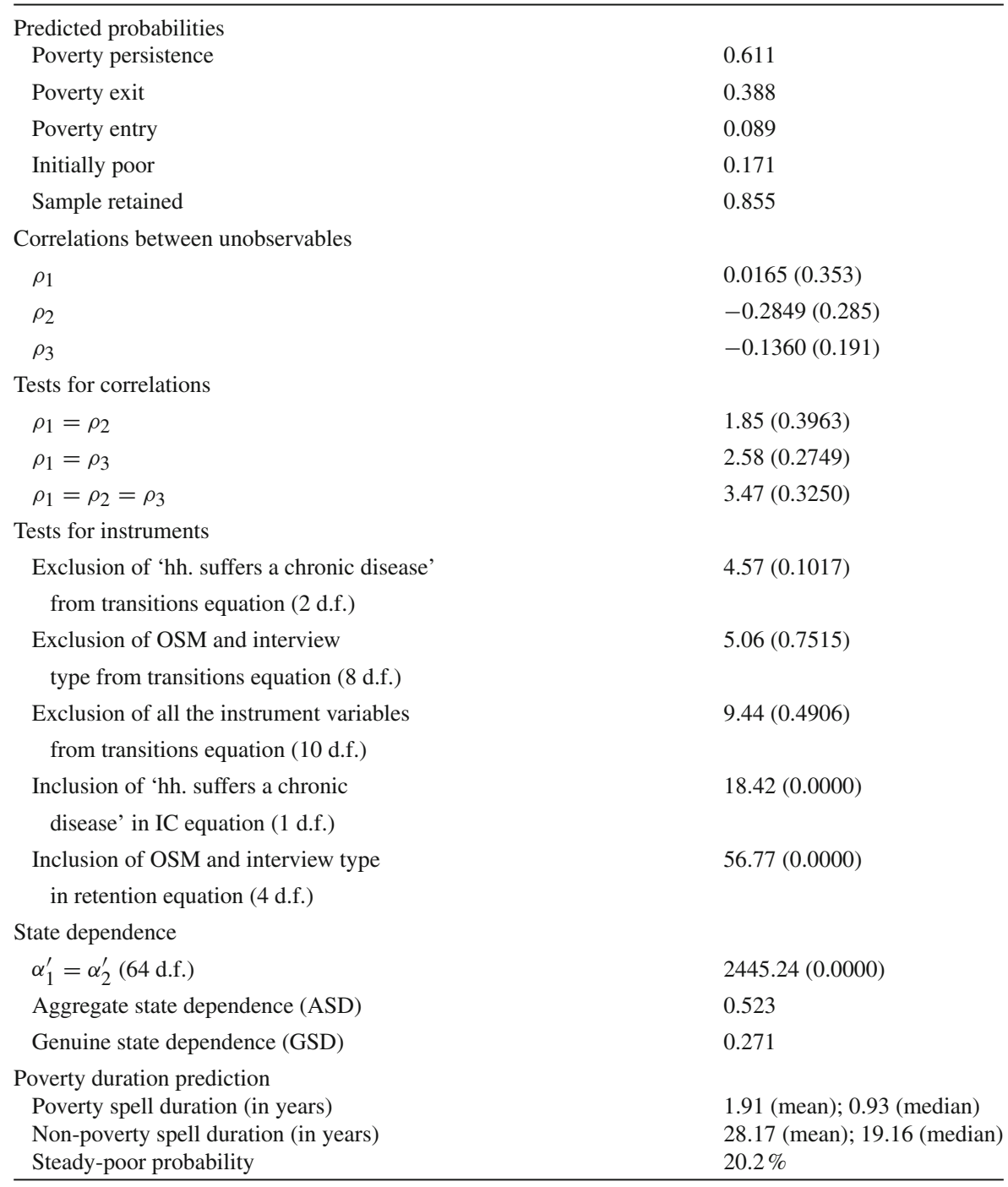

Source: Own construction using the ECHP, 1994-2001. Individuals aged 25 to 64

\subsection{State dependence}

Cappellari and Jenkins (2004a) define aggregate state dependence (ASD) as the simple difference between the probability of being poor at $t$ for those being poor at $t-1$ and the probability of being poor at $t$ for those who were not poor at $t-1$. Thus, 


$$
\begin{aligned}
A S D & =\left(\frac{\sum_{i \in\left(P_{i t-1}=1\right)}\left(\operatorname{Pr}\left(P_{i t}=1 \mid P_{i t-1}=1\right)\right)}{\sum_{i} P_{i t-1}}\right) \\
& -\left(\frac{\sum_{i \in\left(P_{i t-1}=1\right)}\left(\operatorname{Pr}\left(P_{i t}=1 \mid P_{i t-1}=0\right)\right)}{\sum_{i}\left(1-P_{i t-1}\right)}\right)
\end{aligned}
$$

The estimated value of the aggregate state dependence is 0.523 - very close to that obtained by Cappellari and Jenkins (2004a) for Britain (0.526) and by Buddlemeyer and Verick (2007) for Australia (0.520). However, and as already argued, it is important to distinguish between state dependence that is the result of heterogeneity and that of genuine (or true) state dependence (GSD). The former occurs because certain individual characteristics increase the probability of being poor and those characteristics may exhibit persistence over time. The latter occurs when the experience of poverty at the base year increases in itself the chances of being poor the following year.

In the framework of the model presented here, a simple Wald test of absence of genuine state dependence can be formulated as $H_{0}: \alpha_{1}^{\prime}=\alpha_{2}^{\prime}$. If the null hypothesis is not rejected, it means that poverty status at $t$ does not depend on poverty status at $t-1$ since the overall effect of poverty entry is the same as that of poverty persistence and no sign of GSD exists. Our estimates prove that this is not the case. The null hypothesis of no genuine state dependence is rejected with a $p$-value of 0.000 .

Moreover, we compute GSD by averaging throughout the sample the predicted probability of being poor at $t$ given poor at $t-1$ minus the probability of being poor at $t$ given not poor at $t-1$. Note that GSD, as opposed to ASD, controls for individual observed and unobserved heterogeneity. Formally, it can be computed as follows:

$$
G S D=\left(\frac{1}{N}\right) \sum_{i=1}^{N}\left[\operatorname{Pr}\left(P_{i t}=1 \mid P_{i t-1}=1\right)-\operatorname{Pr}\left(P_{i t}=1 \mid P_{i t-1}=0\right)\right]
$$

Based on our model estimates, GSD in the Spanish case amounts to 0.271 - which is between that obtained in the British case (0.310) by Cappellari and Jenkins (2004a) and in the Australian one (0.260) by Buddelmeyer and Verick (2008). ${ }^{27}$ Thus, in Spain, poverty in a given period increases the probability of being poor in the following period relative to another individual with identical characteristics that was not initially poor. About half the aggregate state dependence is genuine. ${ }^{28}$ Our findings highlight the

\footnotetext{
27 Fusco and Islam (2011) obtain a value of 0.38 and 0.70 for GSD and ASD, respectively for the case of Luxembourg. And, Faye et al. (2011) estimate GSD to be $90 \%$ of ASD in Nairobi's slums. However, note that their data set consists of only two waves.

${ }^{28}$ In order to be able to compare these results, and following Wooldridge (2005), we also estimate a dynamic random-effects probit model for poverty at $t$ that controls for state dependence, unobserved heterogeneity and initial conditions, which assumes a certain correlation between time-varying covariates and the specific-effect (see Stewart 2007) and with explanatory variables referred to $t-1$. We obtain fairly similar results with an ASD of 0.472, GSD of 0.227 and a percentage GSD/ASD of $48 \%$. (Results available from the author on request.) Note, however, that the more generally used specification by which explanatory variables refer to the same period as the dependent variable (as in Gradín and Cantó 2011) results in a lower degree of genuine state dependence which questions whether the fulfilment of the strict exogeneity assumption overstates GSD.
} 
balanced need for tax-benefit policies and those that centre on education, training and the acquisition of skills - both types of policy are called for given that individual heterogeneity and genuine state dependence are similarly relevant for explaining poverty in Spain.

Our findings in Table 6 are completed by computing the mean duration of a poverty spell $\left(1 / 1-s_{i t}\right)$, the median duration of a poverty spell $\left(\log (0.5) / \log \left(s_{i}\right)\right)$, the mean duration of a non-poverty spell $\left(1 / e_{i}\right)$, the median duration of a non-poverty spell $\left(\log (0.5) / \log \left(1-e_{i}\right)\right)$ and the unconditional probability of being poor $\left(1 / e_{i}+1-s_{i}\right)$ (see Boskin and Nold 1975, for a full derivation of this formulae and an application to welfare subsidies recidivism). As shown, a poverty spell in Spain lasts an average of nearly two years, while non-poverty spells around 14 times longer.

\subsection{Observed heterogeneity}

Table 6 shows the coefficients and marginal effects for the probability of poverty entry and persistence and Table 7 presents those of retention and base year poverty. It is worth noting that more covariates are significant in the case of entries as opposed to persistence which is consistent with the fact that recurrent poverty affects more heterogeneous individuals which, in turn, highlights how policies should not only be targeted at poor individuals but also at those at risk of falling into it (Jenkins 2011).

Most characteristics of heads of households are statistically significant in explaining poverty entry. Having no formal qualifications, or being self-employed, unemployed or of immigrant origin are positively related to it. Thus, labour market income instability is associated with entries while being an immigrant is clearly the most important risk factor-it increases the chance by $14 \%$. However, age is negatively related to poverty entry but this effect reverses when getting older (which probably reflects upward mobility in the labour market) and also having completed at least secondary school. For instance, living in a household whose head has a university degree reduces the probability of entry by $18.8 \%$ in comparison to someone who only completed primary school. As for demographic characteristics of the household, the presence of children older than 2 increases the chances of entry while cohabiting with older adults or there being other workers in the household reduces it. ${ }^{29}$

Low educational qualifications and having a head of household of immigrant origin are positively associated with poverty persistence. Interestingly, cohabiting with people aged 19-24 reduces the probability of being permanently poor as opposed to thereby having individuals aged 12-15. In Spain, during the analysed period nearly $40 \%$ of individuals aged 19-24 that were living with their parents were working. The help-effect provided by young people to their families has been documented before by Cantó and Mercader (2001) and Ayllón (2009). Again, the number of workers in

\footnotetext{
29 Remember that our model includes individuals from 25 to 64 years of age. Therefore, it does not reflect the economic conditions of elderly households, which are normally in greater economic hardship than the overall population. However, the covariate reflects the effect of the presence of an elderly individual in a younger household possibly income pooling his/her retirement pension.
} 


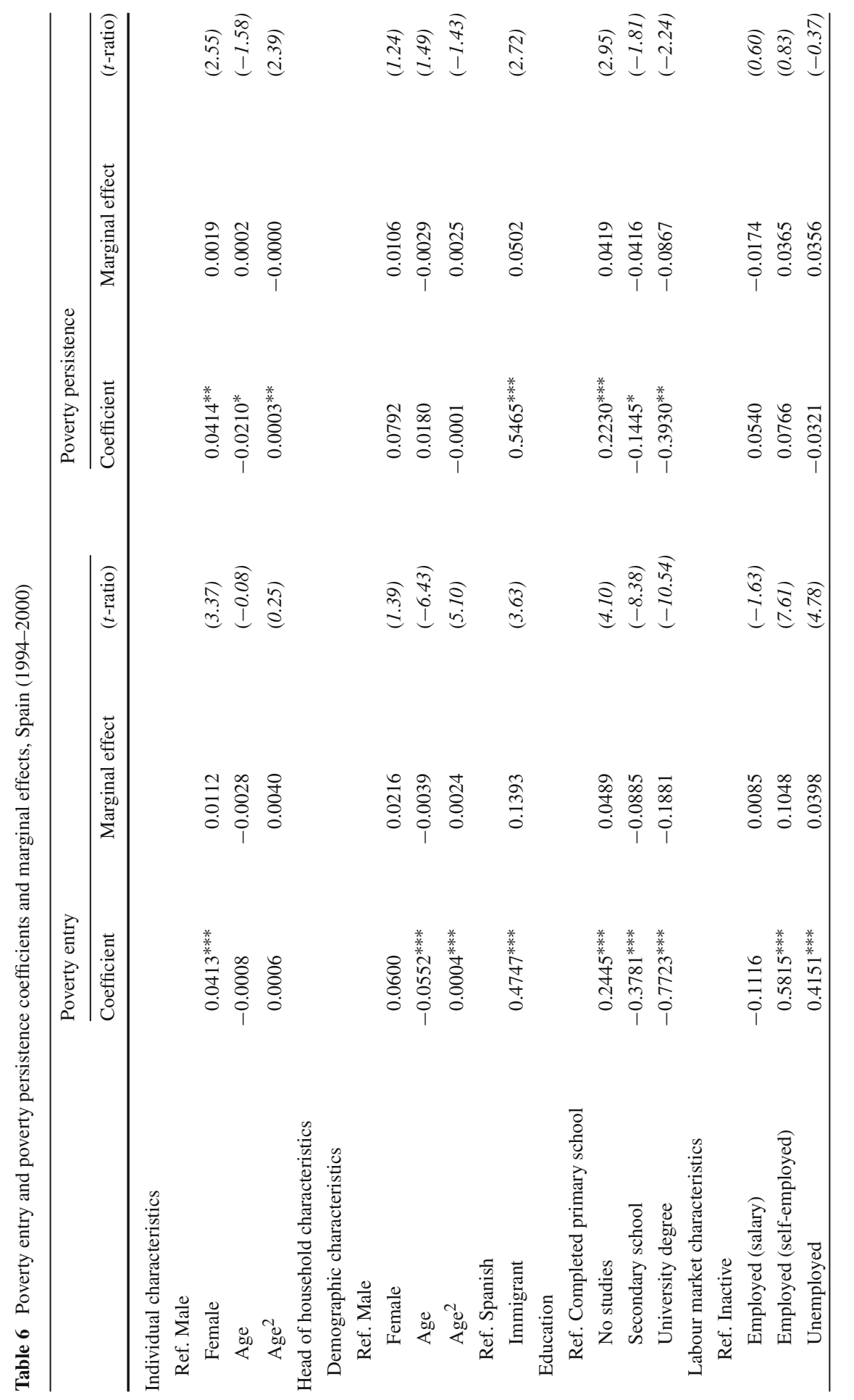




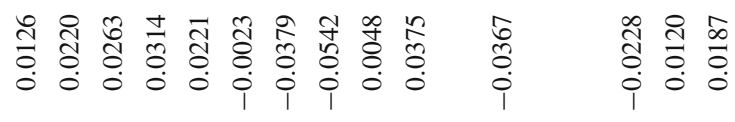

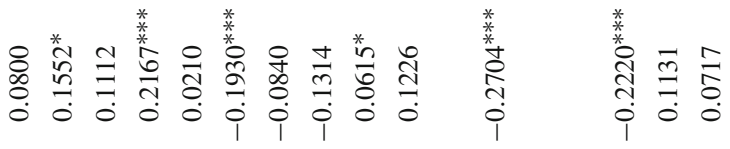

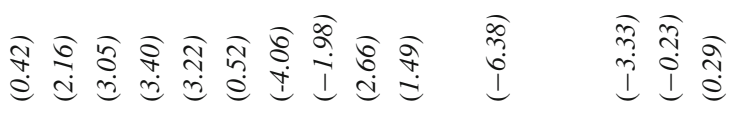

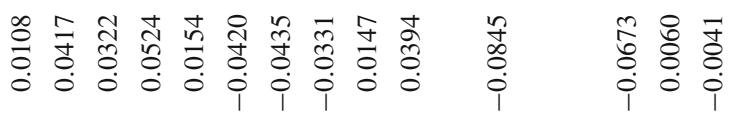

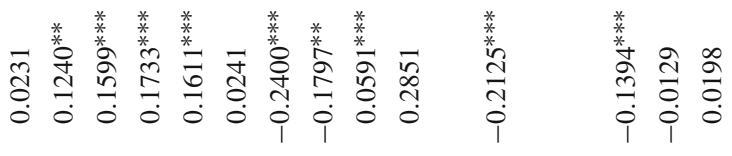

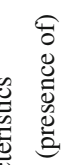

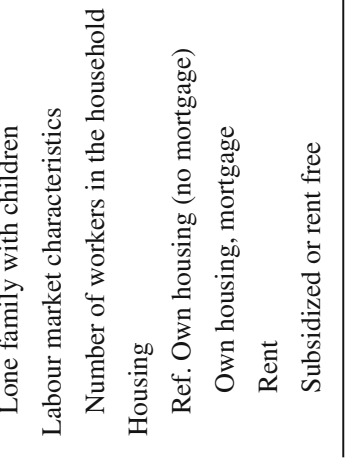




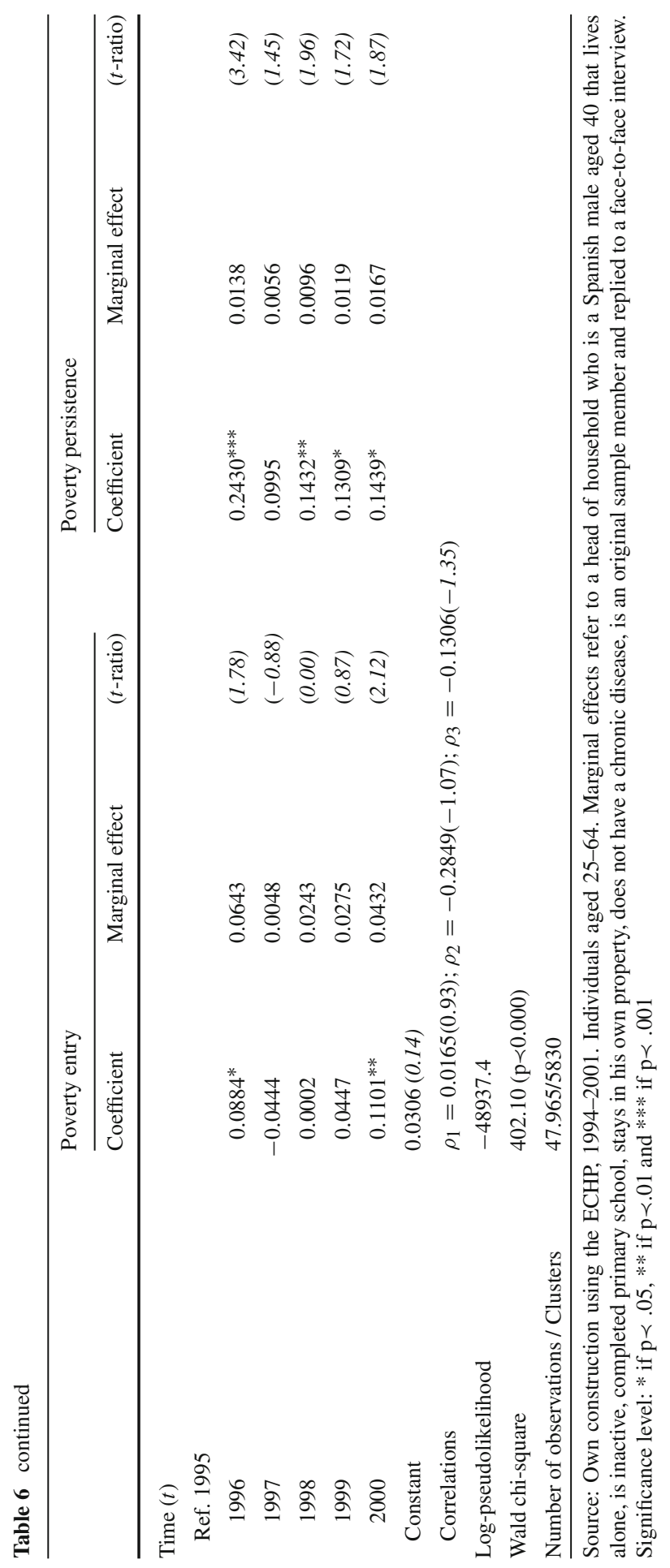




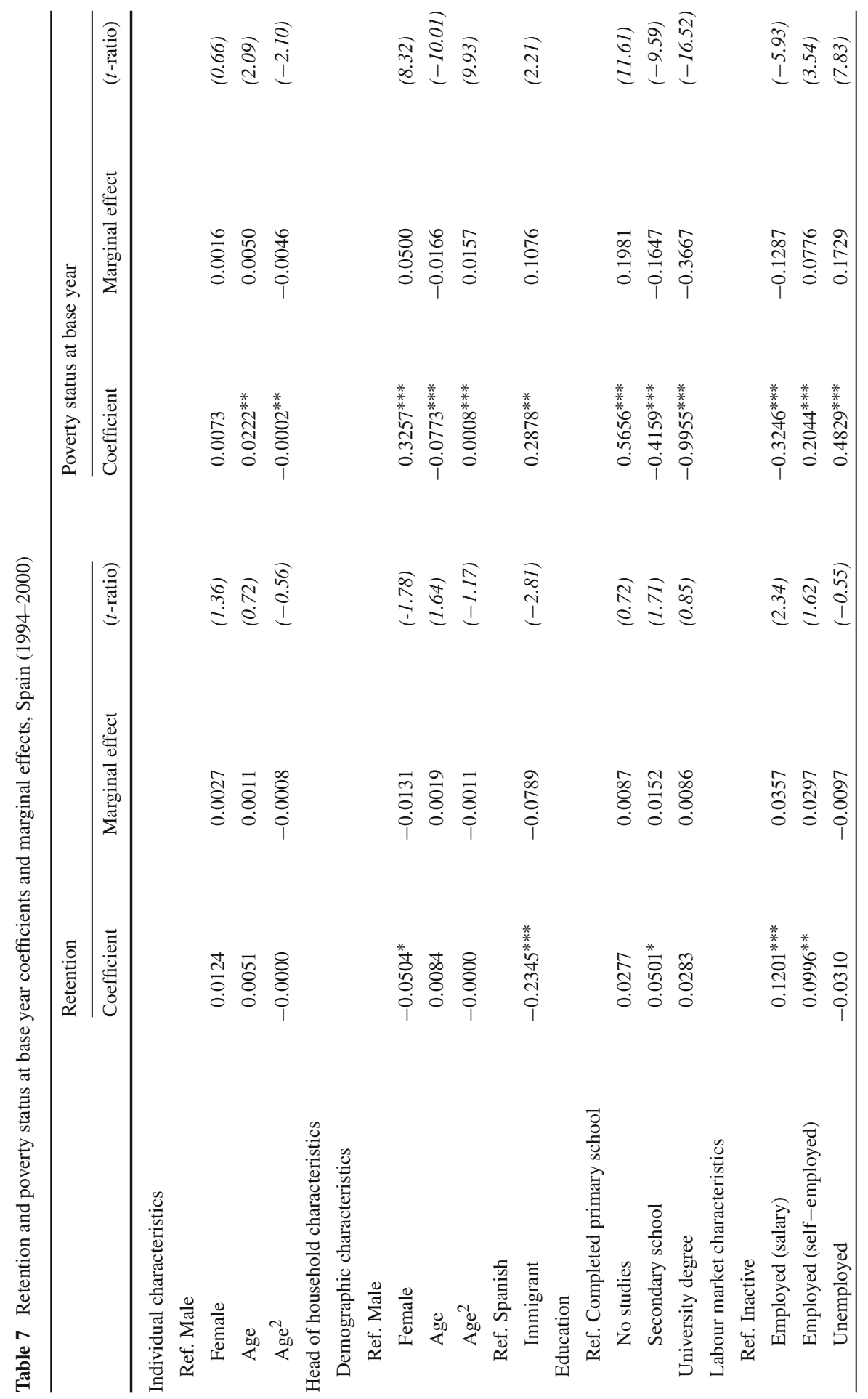




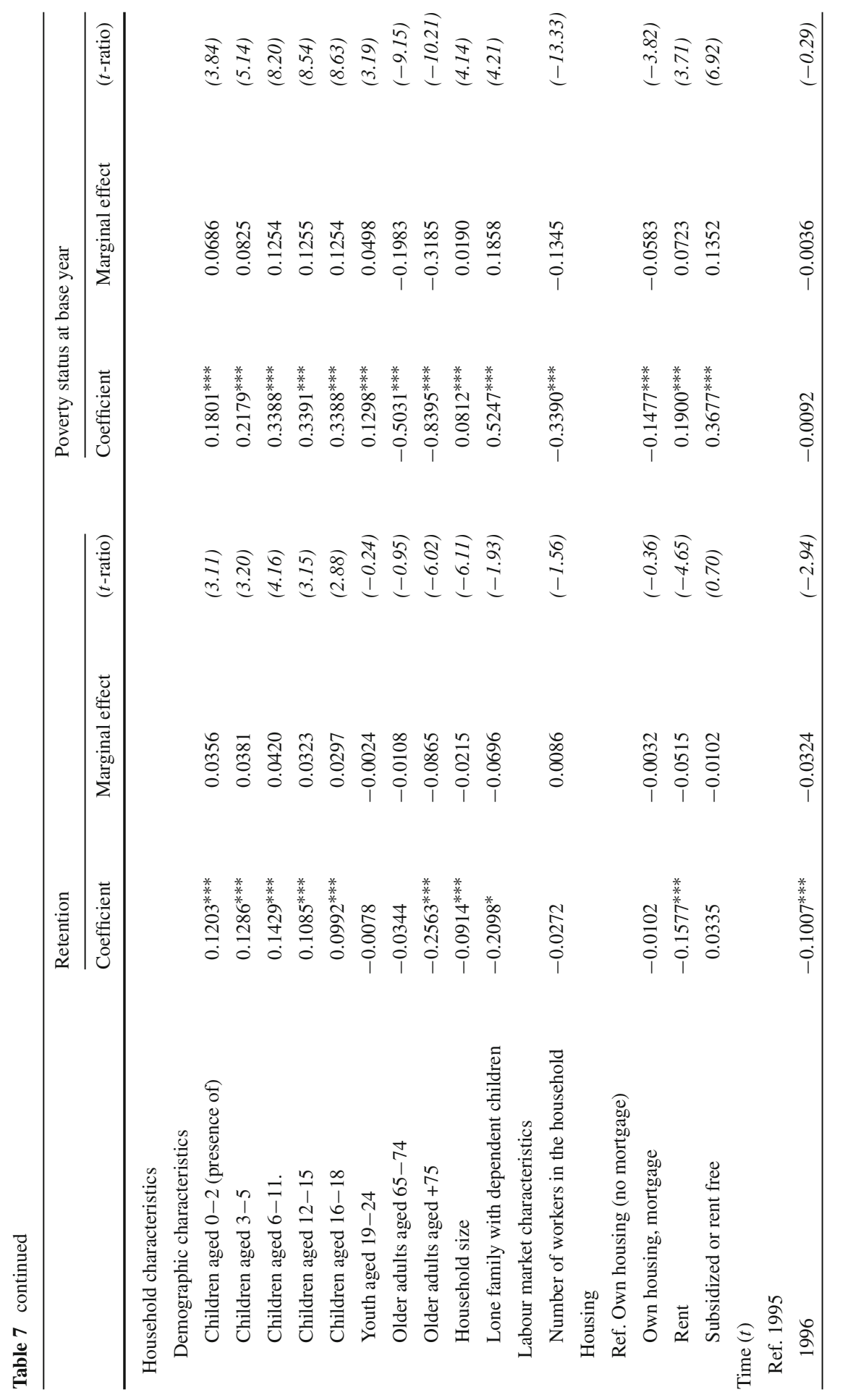




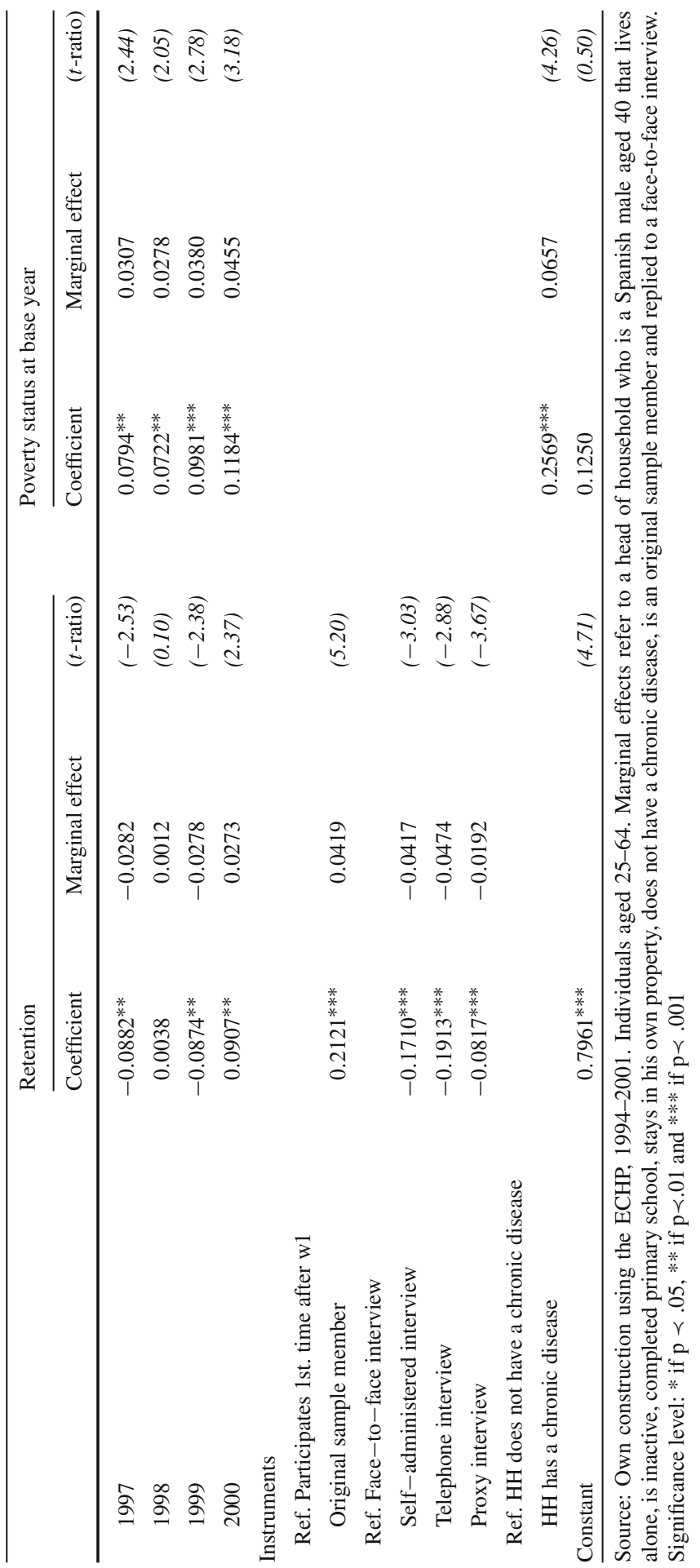


the household is negatively related to finding individuals constantly below the poverty line. ${ }^{30}$

Nearly all coefficients in the base year poverty status equation are statistically significant and have the expected sign. Finally, characteristics that we believe may give stability to a household, such as having children or being employed, are positively related with sample retention, while being an immigrant, living in rented housing or cohabiting with someone older than 75 are negatively associated with it.

\subsection{Robustness checks}

Our robustness checks have focused on the sensitivity of the results to the choice of poverty line, to the definition of poverty transitions and to individual heterogeneity within the initially non-poor group.

The first rows in Table 8 show the estimates of the cross-equation correlations, predicted probabilities, ASD and GSD estimates depending on different poverty thresholds. Interestingly, the results are sensitive to the poverty line with the same model specification. When the poverty line is set at 40 or $50 \%$ of the median, the correlation between unobservables affecting poverty transitions and poverty status at the base year $\left(\rho_{3}\right)$ is negative and statistically significant at a $95 \%$ confidence level which indicates that individuals more likely to be observed as poor in the base year are less likely to remain poor in comparison with the non-poor group. In other words, the lower the level of household equivalent income at $t-1$, the greater the chances of a change in poverty status between $t-1$ and $t$. Ignoring this endogeneity would lead to an underestimation of poverty persistence when poverty is more extremely defined-note the important differences between predicted and raw probabilities. Cappellari and Jenkins (2004a) also obtain a negative value for this correlation with data from the BHPS and argue that it can be interpreted as an example of Galtonian regression towards the mean.

As defined in Barnett et al. (2005), regression to the mean occurs when we observe repeated measurements of the same subject, because relatively high or relatively low observations are likely to be followed by less extreme ones-a phenomenon first discussed by Galton in 1886 in his study of hereditary stature (see Stigler 1999). As argued by Stewart and Swaffield (1999), note that those with very low equivalent household income at $t-1$ have a greater chance of their poverty status changing the lower the poverty threshold is. Regression towards the mean is stronger for values at the extreme. ${ }^{31,32}$ Additionally, this result helps to explain the findings in our

\footnotetext{
30 In a very similar fashion, Cantó et al. (2012) find that poverty recurrence is most importantly related to there being children in the household and being self-employed while chronic poverty is associated with low qualifications, less wage earners and a head of household having a fixed-term contract.

31 Nevertheless, we checked that a trimming of 1 or $2 \%$ of both tales of income distribution is not sufficient to eliminate regression towards the mean. A $5 \%$ trimming results in $\rho_{3}$ being not precisely estimated. However, the correlation between unobservables affecting retention and initial conditions $\left(\rho_{1}\right)$ becomes negative and strongly significant, which may indicate a trade-off between initial conditions and retention endogeneity.

32 The fact that when setting the poverty line at $60 \%$ of the median none of the correlations are precisely estimated in the Australian and Spanish cases may indicate a better sample design of the HILDA dataset
} 


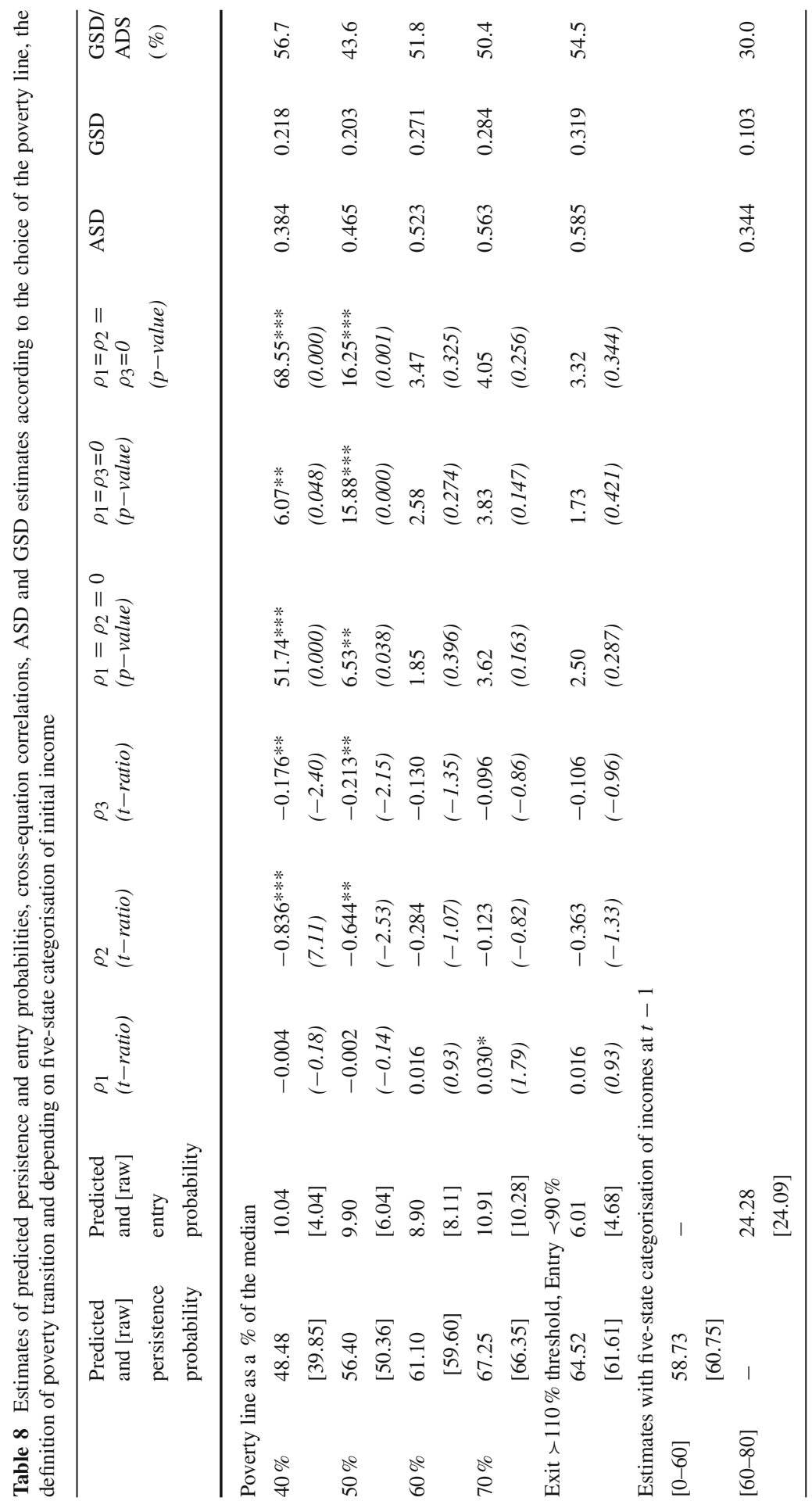




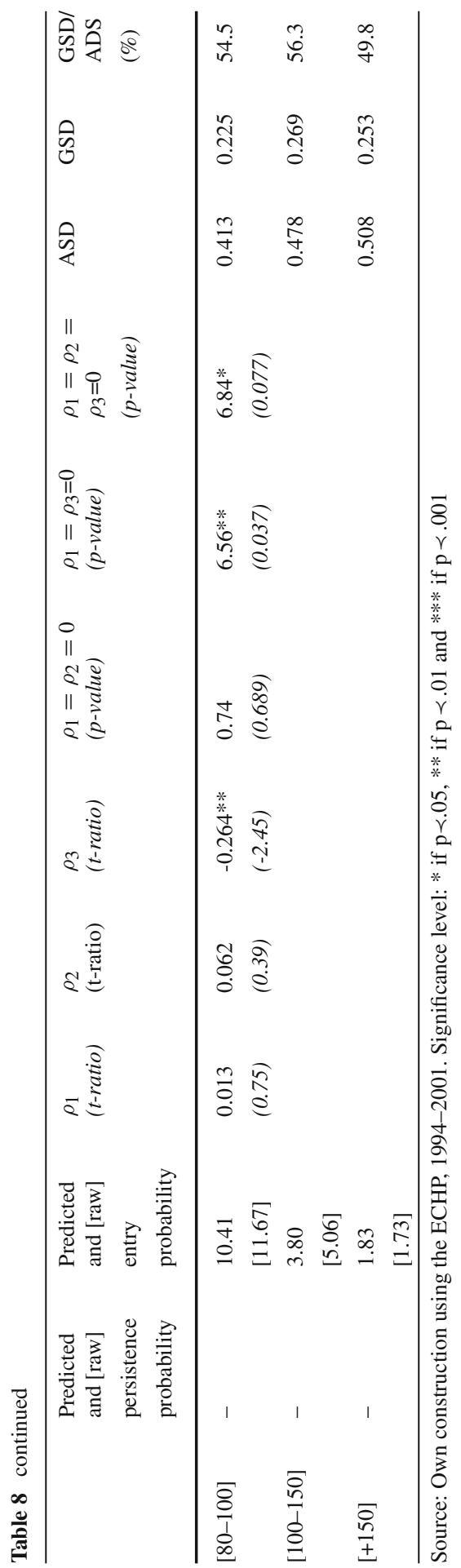


descriptive analysis, whereby exit rates were highest for individuals at the very bottom of the income distribution than for those between 20 and $40 \%$ of the median-see Table 4 . The results are possibly indicating a certain degree of measurement error at the extremes of the income distribution.

Furthermore, when poverty is defined as below 40 or $50 \%$ of the median, note how $\rho_{2}$ is also negative and statistically significant, meaning that unobservables that make individuals more likely to be observed successively in the panel also make them less likely to remain poor or fall into poverty compared to those that attrit. It is reasonable to believe that those individuals living in the worst economic conditions may have more unstable accommodation (so they are more difficult to trace) or may simply be less interested in the survey (for example, due to demoralisation). If we do not take this into account, persistence and entry into deep economic hardship would be underestimated.

ASD estimates increase as the poverty line does likewise. However, note how the percentage GSD/ASD is greatest when the poverty line is more extremely defined ( $40 \%$ of the median). This means that individual heterogeneity is less important for explaining persistence-individuals above and below the threshold are less heterogeneous. However, at the bottom of the distribution, GSD exerts its greatest influence. These results indicate that poverty reduction among the poorest households should be tackled more effectively by income-support policies (namely, transfers) as individual heterogeneity is less important for explaining more severe poverty. As for the remaining poverty lines, no clear pattern emerges in terms of percentage GSD/ASD.

Another question that has frequently been considered in the literature is the possibility of transitions being the result of a very small change in income around the poverty line. As stated by Bane and Ellwood (1986), "The poverty line is an arbitrarily defined concept, and small 'random' changes in income can move people across the line, creating a 'spell' even though no change of any significance to the individual involved occurred" (Bane and Ellwood 1986, p. 7). In order to reduce the potential bias caused by measurement error, in the second panel in Table 8, we define exits from (and entries into) poverty as being when household equivalent post-transition income is greater (or less) than $110 \%$ (90\%) of the poverty line. As expected, both ASD and GSD are among the highest of all estimated models and so the percentage GSD/ASD indicates that a better filter for genuine poverty transitions is in place. Nonetheless, cross-equation correlations are not significant as in our main estimation.

Finally and as already indicated by Cappellari and Jenkins (2004a), GSD results may be driven by the major heterogeneity found among initially non-poor individuals. In order to check the robustness of our state dependence estimates, we split the group of individuals above the poverty line into four categories according to their household equivalent income relative to the median of distribution (60-80\% of the median, 80-100\%, 100-150\% and more than 150\%) and com-

Footnote 32 Continued and the Spanish component of the ECHP as opposed to the BHPS given that the more extreme a working sample is relative to the population, the more room there is to regress towards the mean. 
pute four different measures of ASD and GSD depending on the income band to which the individual belongs at $t-1$ (see Cappellari and Jenkins 2004a, Section 5, for full details). The third panel in Table 8 shows how poverty entry rates decrease as base year income increases. The absence of GSD was rejected in all income bands by statistical tests (not shown) with $p$-value $\prec 0.000$ indicating that previous results were not driven by ignoring heterogeneity among the non-poor group.

\section{Conclusions}

The main aim of this paper has been to provide an analysis of the determinants and mechanisms behind poverty dynamics in Spain by focusing on poverty entries and persistence among the working-age population. Model estimates have shown that current poverty is highly determined by past poverty experiences in Spain: about $50 \%$ of aggregate state dependence is genuine: the experience of poverty in a given year increases in itself the chances of being poor in the following year. Moreover, we have shown that poverty persistence is strongly related with living with a head of household that has no education, being an immigrant or cohabiting with teenagers. However, living with employed individuals, residing with young people and, especially, having a university degree are negatively associated with poverty persistence. Poverty entries are reversely associated with head of household's age, cohabitation with elderly people, having at least a secondary school certificate and the number of employed individuals in the household. Self-employment, unemployment, illiteracy, parenting and migration are all associated with poverty entry.

Our findings have important consequences for policy design as they call for a comprehensive and coordinated strategy against poverty that should equally focus on income-support policies - in order to break the vicious circle of consecutive poverty — and on individual and household characteristics — promoting employability via education and training, enhancing the conciliation of working and family life, supporting families with children and teenagers or contributing to immigrant integration, among many others.

The methodology used in the paper has enabled the assessment of whether sample retention and initial conditions are endogenous selection processes to poverty transitions not only via observed heterogeneity but also through unobserved one. Following the simultaneous model proposed by Cappellari and Jenkins (2004a) and using Maximum Simulated Likelihood, we have found that unobservables affecting poverty status at base year and/or retention are not correlated with unobservables associated with poverty transitions when using the standard poverty line defined as $60 \%$ of the median of the household equivalent income. Therefore, and as for unobserved heterogeneity, poverty transitions can be estimated separately from initial conditions and retention for the Spanish case when using the ECHP. In this regard, our results reinforce those of other researchers that have studied poverty dynamics without accounting for the possible correlations between unobservables 
related with transience, attrition and initial conditions (see the Review section of this paper).

Moreover, from our robustness checks, we have found that unobservables affecting poverty status at the base year and poverty transience are significant and negatively correlated when the poverty line moves to 40 or $50 \%$ of the median. Thus, unobservables that make individuals more likely to be found at the lowest extreme of income distribution in a given year also make them less likely to remain in that position in the following period. As argued, this result can be seen as a Galtonian regression towards the mean by which relatively high or low observations of a subject are likely to be followed by less extreme ones. Similarly, individuals that are more likely to be observed successively in the panel are less likely to remain poor or fall into poverty compared to those that attrit. Ignoring the endogeneity of both processes would underestimate our poverty persistence and entry predictions for those in the worst economic hardship.

There are different avenues for future research. So far, we have been able to measure the degree of poverty genuine state dependence but little is known about what lies behind it. Disentangling the different possible sources related to this scarring effect should be highly relevant in policy design. Also, one could consider the possibility of accounting for more sophisticated dynamics than those presented here, thus, getting closer to the structure of duration dependence models. Finally, future research could also reassess our results by applying this methodology to the new EU-SILC data once the panel has become more mature and considering it is meant to become the reference source for comparative statistics on income, poverty and social exclusion in Europe. As mentioned, this methodology adapts especially well to the rotational nature of the panel.

Acknowledgments The present research was (co-)funded by the European Commission under the 6th Framework Programme's Research Infrastructures Action (Trans-national Access contract RITA 026040) hosted by IRISS-C/I at CEPS/INSTEAD, Differdange (Luxembourg). I am grateful for the warm hospitality I received at CEPS/INSTEAD and at the Institute for Research on Poverty at the University of WisconsinMadison. I like to also thank Martin Biewen, Olga Cantó, Alessio Fusco, David Pujolar, Xavi Ramos and Philippe Van Kerm as well as participants at the XI Encuentro de Economía Aplicada (2008), at the 20th EALE Annual Conference (2008), at the UNU-WIDER Conference 'Frontiers of Poverty Analysis' (2008) and at the 2nd General Conference of the International Microsimulation Association (2009) for comments on an earlier version of this paper. Any errors or misinterpretations are my own. Financial support is also greatly acknowledged from the Spanish project ECO2010-21668-C03-02 and XREPP (Direcció General de Recerca).

Open Access This article is distributed under the terms of the Creative Commons Attribution License which permits any use, distribution, and reproduction in any medium, provided the original author(s) and the source are credited.

\section{Appendix}

See Tables 9 and 10. 
Table 9 Headcount ratio (whole population) and number of individual-wave observations by income definition

\begin{tabular}{lllllll}
\hline \multirow{2}{*}{ Wave } & \multirow{2}{*}{ Income refers to } & \multicolumn{2}{c}{ Income definition [1] } & & \multicolumn{2}{c}{ Income definition [2] } \\
& & Poor & Obs & & Poor & Obs. \\
\hline $1(1994)$ & 1993 & 19.59 & 22.837 & & - & \\
$2(1995)$ & 1994 & 18.98 & 20.458 & & 18.66 & 18.677 \\
$3(1996)$ & 1995 & 17.97 & 19.278 & & 18.21 & 17.488 \\
$4(1997)$ & 1996 & 20.34 & 17.916 & & 20.63 & 16.183 \\
$5(1998)$ & 1997 & 18.18 & 16.598 & & 18.31 & 15.026 \\
$6(1999)$ & 1998 & 18.89 & 15.863 & & 18.89 & 14.168 \\
$7(2000)$ & 1999 & 18.02 & 14.784 & & 18.48 & 13.349 \\
$8(2001)$ & 2000 & 18.82 & 14.270 & & 18.86 & 12.935 \\
\hline
\end{tabular}

Source: Own construction using the ECHP, 1994-2001. [1] Household income refers to $t-1$ but the equivalence scale refers to $t$. [2] Household income and equivalence scale refer to $t$. Cross-sectional weights used. Notice that the headcount ratio for 1993 cannot be computed as we do not know household composition for this year. In few cases where there is missing income information for one household members, we were able to impute to that individual the income information given in the survey for within household nonresponse $(0.37 \%$ of the individuals-waves sample). Also, note that household income for year $t-1$ cannot be computed in those households where one of the household members dies at $t$. In these cases, we proxied his/her personal income at $t$ with the one reported at $t-1(0.30 \%$ of the individuals-wave sample)

Table 10 Poverty status at $t$ conditional of poverty status at $t-1$ in Spain with missing income information and by income definition (whole population)

\begin{tabular}{llll}
\hline Year & $t$ & & Missing \\
\cline { 2 - 4 } & Not poor & Poor & \\
\hline$[1] t-1$ & & & 11.46 \\
Not poor & 80.80 & 7.73 & 11.71 \\
Poor & 34.50 & 53.79 & 11.51 \\
Total & 72.05 & 16.44 & 14.42 \\
{$[2] t-1$} & & & 14.12 \\
Not poor & 78.22 & 7.36 & 14.37 \\
Poor & 32.83 & 53.06 & 15.98 \\
Total & 69.65 & & 1104 \\
\hline
\end{tabular}

Source: Own construction using the ECHP, 1994-2001. [1] Household income refers to $t-1$ but the equivalence scale refers to $t$ (1993-2000). [2] Household income and equivalence scale refer to $t$ (19942000). Cross-sectional weights used

\section{References}

Aassve A, Burgess S, Dickson M, Propper C (2006) Modelling poverty by not modelling poverty: an application of a simultaneous hazards approach to the UK. CASEpaper, vol 106, Centre for Analysis of Social Exclusion

Amuedo-Dorantes C, Serrano-Padial R (2010) Labour market flexibility and poverty dynamics: evidence from Spain. Labour Econ 17(4):632-642

Arranz JM, Cantó O (2007) Measuring the effect of spell recurrence on poverty dynamics. Evidence from Spain. Papeles de Trabajo 5/08, Instituto de Estudios Fiscales 
Arranz JM, Cantó O (2011) Measuring the effect of spell recurrence on poverty dynamics_Evidence from Spain. J Econ Inequal (forthcoming)

Arulampalam W, Booth A, Taylor M (2000) Unemployment persistence. Oxford Econ Pap 52(1):24-50

Ayala L, Navarro C, Sastre M (2006) Cross-country income mobility comparisons under panel attrition: the relevante of weighting schemes. Working Paper Series 2006-47, ECINEQ

Ayllón S (2009) Poverty and living arrangements among youth in Spain, 1980-2005. Demogr Res 20(17):403-434

Bane M, Ellwood D (1986) Slipping into and out of poverty: the dynamics of spells. J Human Resour 21(1):1-23

Bárcena ME, Cowell FA (2006) Static and dynamic poverty in Spain: 1993-2000. Hacienda Pública Española/Revista de Economía Pública 179(4/2006):51-77

Bárcena ME, Fernández MA, Lacomba AB, Martín RG (2004) Dinámica de la pobreza a corto plazo en España y Reino Unido a través de los datos del Panel de Hogares Europeo. Estadística Española 46(157):461-481

Barnett AG, Van Der Pols J, Dobson A (2005) Regression to the mean: what it is and how to deal with it. Int J Epidemiol 34(1):215-220

Biewen M (2005) The covariance structure of East and West German incomes and its implications for the persistence of poverty and inequality. German Econ Rev 6(4):445-469

Biewen M (2009) Measuring state dependence in individual poverty histories when there is feedback to employment status and household composition. J Appl Econom 24(7):1095-1116

Boskin MJ, Nold FC (1975) A Markov model of turnover in aid to families with dependent children. J Human Resour 10(4):476-481

Buddelmeyer H, Verick S (2008) Understanding the drivers of poverty dynamics in Australian households. Econ Record 84(266):310-321

Burgess S, Propper C (1998) An economic model of household income dynamics with an application to poverty dynamics among American women. CASEpaper, vol 9. Centre for Analysis of Social Exclusion, London School of Economics, UK

Cantó O (2002) Climging out of poverty, falling back in: low income stability in Spain. Appl Econ 34:1903-1916

Cantó O (2003) Finding out the routes to escape poverty: the relevance of demographic vs. labor market events in Spain. Rev Income Wealth 49(4):569-588

Cantó O (2006) Poverty statics and dynamics: does the accounting period matter? Int J Social Welf 15(3):209-218

Cantó O (2007) What helps households with children in leaving poverty? Evidence from Spain. Res Econ Inequal 14(1):1-29

Cantó O, Grad C, Del Río C (2012) Pobreza crónica, transitoria y recurrente en España. Revista de Economía Aplicada 58:69-94

Cantó O, Mercader M (2001) Pobreza y familia: son los jóvenes una carga o una ayuda?. Papeles de Economía Española 88:151-165

Cappellari L, Jenkins SP (2002) Who stays poor? Who becomes poor? Evidence from the British Household Panel Survey. Econ J 112(478):C60-C67

Cappellari L, Jenkins SP (2003) Multivariate probit regression using simulated maximum likelihood. Stata J 3(3):278-294

Cappellari L, Jenkins SP (2004a) Modelling low income transitions. J Appl Econom 19:593-610

Cappellari L, Jenkins SP (2004b) Modelling low pay transition probabilities accounting for panel attrition. non-response and initial conditions. Working Paper 2004-08. ISER

Cappellari L, Jenkins SP (2006) Calculation of multivariate normal probabilities by simulation with applications to maximum simulated likelihood estimation. Stata J 6(2):156-189

Debels A, Vandecasteele L (2005) Correcting the income time lag in panel data: the impact on income and poverty dynamics. unpublished Working Paper

Debels A, Vandecasteele L (2008) The time lag in annual household-based income measures: assessing and correcting the bias. Rev Income Wealth 54(1):71-88

Devicienti F (2001) Estimating poverty persistency in Britain. Working Paper Series 1, Laboratorio R. Revelli

Devicienti F, Gualtieri V (2007) The dynamics and persistence of poverty: evidence from Italy. Working Paper Series 63, Laboratorio R. Revelli

Duncan G, Rodgers W (1991) Has children's poverty become more persistent? Am Sociol Rev 56(4):538550 
Faye O, Islam N, Zulu E (2011) Poverty dynamics in Nairobi's slums: testing for true state dependence and heterogeneity effects. CEPS/INSTEAD Working Paper Series 2011-56, CEPS/INSTEAD

Fourage D, Layte R (2003) Duration of poverty spells in Europe. Working Papers 2003-47, European Panel Analysis Group

Fusco A, Islam N (2011) Understanding the drivers of low income transitions in Luxembourg. mimeo

García Mainar I, Toharia L (1998) Paro, pobreza y desigualdad en España: análisis transversal y longitudinal. Ekonomiaz 40:135-165

Gould W, Sribney W (1999) Maximum Likelihood estimation using Stata. Stata Press, College Station

Gradín O (2003) La evolución de la pobreza estática y dinámica en España en el período 1985-1995. Hacienda Pública Española 167-4:87-119

Gradín C, Cantó O (2011) Why are child poverty rates so persistently high in Spain? The Manchester School (forthcoming)

Greene WH (2000) Análisis econométrico, 3rd edn. Prentice Hall, Englewood Cliffs

Haan P, Uhlendorff A (2006) Estimation of multinomial logit models with unobserved heterogeneity using maximum simulated likelihood. Stata J 6(2):229-245

Heckman JJ (1981) Statistical models for discrete panel data. In: Manski CF, McFadden D (eds) Structural analysis of discrete data with econometric applications. MIT Press, Cambridge, pp 114-178

Jenkins SP (2000) Modelling household income dynamics. J Popul Econ 13:529-567

Jenkins SP (2011) Changing fortunes: income mobility and poverty dynamics in britain. Oxford University Press, New York

Jenkins SP, Van Kerm P (2011) Patterns of persistent poverty: evidence from EU-SILC. ISER Working Paper Series 2011-30, Institute for Social and Economic Research

Lillard L, Willis R (1978) Dynamic aspects of earnings mobility. Econometrica 46(5):985-1012

Nicoletti C, Peracchi F (2005) Survey response and survey characteristics: microlevel evidence from the European Community Household Panel. J R Stat Soc Ser A 168(4):763-781

Nilsson W (2012) Heterogeneity or true state dependence in poverty: the tale told by twins. Rev Income Wealth (forthcoming)

OECD (2001) When money is tight: poverty dynamics in OECD countries. Employment Outlook, OECD

OECD (2008) Does income poverty last over time? Evidence from longitudinal data. In: Growing Unequal? Income Distribution and Poverty in OECD countries, chap. 6, pp. 155-175. OECD

Poggi A (2007) Does persistence of social exclusion exist in Spain? J Econ Inequal 5:53-72

Stevens A (1999) Climbing out of poverty, falling back in. J Human Resour 34(3):557-588

Stewart M, Swaffield J (1999) Low pay dynamics and transition probabilities. Economica 66(261):23-42

Stewart MB (2007) The interrelated dynamics of unemployment and low-wage employment. J Appl Econ 22(3):511-531

Stigler SM (1999) Statistics on the table. In: The history of statistical concepts and methods. Harvard University Press, Cambridge

Train K (2003) Discrete choice methods with simulation. Cambridge University Press, Cambridge

Van Kerm P (2004) Une évaluation économétrique des flux vers et hors de la pauvreté en Belgique. IRISS Working Paper Series 2004-04, IRISS at CEPS/INSTEAD

Wooldridge JM (2002) Econometric analysis of cross section and panel data. MIT Press, Cambridge

Wooldridge JM (2005) Simple solutions to the initial conditions problem in dynamic, non linear panel data models with unobserved heterogeneity. J Appl Econom 20:39-54 